\title{
Influence of the temperature of sintering under pressure on the structure and mechanical properties of a composite material $\mathrm{AMg} 2 / \gamma-\mathrm{Al}_{2} \mathrm{O}_{3}$ nanofibres
}

\author{
A. V. Aborkin ${ }^{\dagger, 1}$, D. M. Babin ${ }^{1}$, A. N. Mochanov' ${ }^{1}$, M. I. Alymov² \\ †aborkin@vlsu.ru \\ ${ }^{1}$ Vladimir State University n. a. Alexander and Nikolay Stoletovs, 87 Gorky St., Vladimir, 600026, Russia \\ ${ }^{2}$ Merzhanov Institute of Structural Macrokinetics and Materials Science, RAS, 8 Academician Osipyan St., \\ Chernogolovka, 142432, Russia
}

\begin{abstract}
A nanocrystalline composite powder based on an $\mathrm{AlMg} 2$ alloy reinforced with 1 wt. $\% \gamma-\mathrm{Al}_{2} \mathrm{O}_{3}$ nanofibers was obtained in a planetary mill by mechanical synthesis. It was consolidated by sintering under pressure at a temperature of $300-450^{\circ} \mathrm{C}$ and a pressure of $600 \mathrm{MPa}$. The effect of the temperature of sintering under pressure on the structural-phase composition, density, hardness, and conventional yield stress of bulk composites was studied. For this, X-ray phase analysis, transmission electron microscopy, hydrostatic weighing, and mechanical testing were used. It has been found that an increase in the sintering temperature in this range leads to an increase in the relative density of compacts from 0.87 to 0.98 . Based on the results of $\mathrm{X}$-ray diffractometry, the sizes of coherent scattering regions corresponding to bulk composites consolidated at different temperatures are determined. It is shown that an increase in the consolidation temperature from 300 to $400^{\circ} \mathrm{C}$ leads to a linear increase in the size of coherent scattering regions from 109 to $495 \mathrm{~nm}$, a further increase in temperature to $450^{\circ} \mathrm{C}$ results in a more intensive growth up to $4.2 \mu \mathrm{m}$. In this case, the hardness of the composite material decreases from $206 \pm 13$ to $149 \pm 3 \mathrm{HV}_{10}$, which is due to the occurrence of the reduction processes and the transition of the structure from nanoscale to the micron scale. The maximum conventional yield stress for compression, $791 \pm 58 \mathrm{MPa}$, corresponds to samples consolidated at $350^{\circ} \mathrm{C}$, which is due to the overall effect of dispersion hardening by $\gamma-\mathrm{Al}_{2} \mathrm{O}_{3}$ nanofibres and nanostructuring of the matrix material. An increase in temperature to $450^{\circ} \mathrm{C}$ neutralizes the effect of nanostructuring and leads to a reduction in the conventional yield stress for compression to $632 \pm 30 \mathrm{MPa}$.
\end{abstract}

Keywords: nanofibers $\gamma-\mathrm{Al}_{2} \mathrm{O}_{3}$, mechanical milling, structure, strength.

УДК: 621.762.22: 621.17: 621.18

\section{Влияние температуры спекания под давлением на структуру и механические свойства композиционного материала $\mathrm{AMr} 2$ /нановолокна $\gamma-\mathrm{Al}_{2} \mathrm{O}_{3}$}

\author{
Аборкин А. В. ${ }^{\dagger,}$, Бабин Д. М. ${ }^{1}$, Мочанов А. Н. ${ }^{1}$, Алымов М. И. ${ }^{2}$
}

†aborkin@vlsu.ru

\footnotetext{
${ }^{1}$ Владимирский государственный университет имени Александра Григорьевича и Николая Григорьевича Столетовых, ул. Горького, 87, Владимир, 600026, Россия

${ }^{2}$ Институт структурной макрокинетики и проблем материаловедения им. А. Г. Мержанова РАН, ул. Академика Осипьяна, 8, Черноголовка, 142432, Россия
}

Методом механического синтеза в планетарной мельнице получен нанокристаллический композиционный порошок на основе сплава $\mathrm{AM} 2$, упрочненного 1 вес.\% нановолокон $\gamma-\mathrm{Al}_{2} \mathrm{O}_{3}$. Проведена его консолидация спеканием под давлением при температуре $300-450^{\circ} \mathrm{C}$ и давлении 600 МПа. Изучено влияние температуры спекания под давлением на структурно-фазовый состав, плотность, твердость и условный предел текучести объемных композитов. Для этого использовали методы рентгенофазового анализа, просвечивающей электронной микроскопии, гидростатического взвешивания и механических испытаний. Установлено, что повышение температуры спекания в указанном диапа- 
зоне ведет к росту относительной плотности компактов от 0.87 до 0.98 . На основании результатов рентгеновской дифрактометрии определены размеры областей когерентного рассеяния, соответствующие объемным композитам, консолидированным при различной температуре. Повышение температуры консолидации от 300 до $400^{\circ} \mathrm{C}$ ведет к линейному росту размера областей когерентного рассеяния от 109 до 495 нм, дальнейшее увеличение температуры до $450^{\circ} \mathrm{C}$ способствует более интенсивному росту - 4.2 мкм. При этом уменьшается твердость композиционного материала от $206 \pm 13$ до $149 \pm 3 \mathrm{HV}_{10}$. Это связано с протеканием восстановительных процессов и переходом структуры из нано- в микронный масштаб. Наибольший условный предел текучести на сжатие $791 \pm 58$ МПа, соответствует образцам, консолидированным при $350^{\circ} \mathrm{C}$, что обусловлено суммарным эффектом дисперсного упрочнения нановолокнами $\gamma-\mathrm{Al}_{2} \mathrm{O}_{3}$ и наноструктурирования матричного материала. Повышение температуры до $450^{\circ} \mathrm{C}$ нивелирует эффект наноструктурирования и ведет к снижению условного предела текучести на сжатие до $632 \pm 30 \mathrm{MПа.}$

Ключевые слова: нановолокна $\gamma-\mathrm{Al}_{2} \mathrm{O}_{3}$, механический размол, структура, прочность.

\section{1. Введение}

При создании композитов на основе алюминия и его сплавов в качестве упрочняющих частиц часто используют $\mathrm{Al}_{2} \mathrm{O}_{3}$, что обусловлено его доступностью, низкой стоимостью и высокими свойствами $[1,2]$. При этом, наибольшее распространение получили методы порошковой металлургии, состоящие в механической обработке порошковых смесей в планетарных мельницах $[3,4]$. Например, в работе [5] исследованы структура и механические свойства композиционных материалов на основе алюминия, упрочненного 1-7 об.\% сферических частиц $\alpha-\mathrm{Al}_{2} \mathrm{O}_{3}$ размером 50 нм. Показано, что наиболее эффективное упрочнение достигается при содержании 4 об.\% $\alpha-\mathrm{Al}_{2} \mathrm{O}_{3}$ в матричном материале. Образцам соответствует твердость $78 \mathrm{HV}$ и предел текучести на растяжение 175 МПа. Авторами работы [6] изучено влияние размера и объемной доли упрочняющих частиц на механические свойства композитов на основе алюминия, упрочненного 1-10 об.\% сферических частиц $а-\mathrm{Al}_{2} \mathrm{O}_{3}$ размером 4, 80 и 400 нм. Установлено, что наилучшие механические свойства соответствуют композитам, упрочненным 10 об.\% $\mathrm{Al}_{2} \mathrm{O}_{3}$ с размером частиц 4 нм - микротвердость $185 \mathrm{HV}_{0.5}$ и предел текучести на сжатие 661 МПа.

Другой полиморфной модификацией $\mathrm{Al}_{2} \mathrm{O}_{3}$, которая также может быть эффективно использована в качестве упрочняющего наполнителя, но имеет меньшую плотность, чем а-модификация, является $\gamma-\mathrm{Al}_{2} \mathrm{O}_{3}$.

В серии работ [7 - 9] представлены результаты синтеза и изучения объемных композитов на основе алюминиевой матрицы, упрочненной in situ наночастицами $\gamma-\mathrm{Al}_{2} \mathrm{O}_{3}$. При этом композиты были получены консолидацией алюминиевого порошка с помощью равноканольного углового прессования с противодавлением. Так в работе [7] при консолидации ультрадисперсного порошка алюминия получены нанокомпозиционные материалы с предельной прочностью на сжатие 740 МПа и микротвердостью 2285 МПа. Анализ микроструктуры показал, что достигнутая высокая прочность и микротвердость были получены из-за присутствия нанокристаллического алюминия и in situ наночастиц $\gamma-\mathrm{Al}_{2} \mathrm{O}_{3}$ размером 5-10 нм, а также остаточного аморфного оксида алюминия. Последующая работа этих авторов [8] направлена на изучение влияния старения ультрадисперсного порошка алюминия на способность консолидации и ис- следование возможности повышения пластичности посредством создания объемных композитов с бимодальной структурой за счет использования механической смеси ультрадисперсных и микроразмерных порошков. В работе [9] для получения объемных нанокомпозитов использовали нано- и микроразмерные порошки алюминия, как в исходном состоянии, так и после механической обработки в планетарной мельнице, а также механическую смесь данных порошков. C помощью рентгеновской дифракции, дифференциальной сканирующей калориметрии и термогравиметрического анализа изучен процесс трансформации оксидного слоя на частицах алюминия. Показано, что композиты из наноразмерного порошка имеют значительно более высокую твердость (около $166 \mathrm{HV})$, чем те, что получены консолидацией микроразмерного порошка (29 HV). Первым соответствовала высокая прочность на сжатие и низкая пластичность. В то время как образцы, полученные с использованием микроразмерного порошка, демонстрировали вязкое поведение, но значительно более низкую прочность. Образец, консолидированный из механически обработанной смеси микро- и наночастиц алюминия, показал компромисс между пластичностью и прочностью (11\% и $350 \mathrm{MПа,} \mathrm{соответственно).} \mathrm{В} \mathrm{работе} \mathrm{[10]} \mathrm{проведено}$ комплексное исследование композитов на основе сплава $\mathrm{AlMg} 5$, упрочненного $0.2-1$ об.\% $\gamma-\mathrm{Al}_{2} \mathrm{O}_{3}$ с средним размером частиц 23 нм. Предел текучести на растяжение и твердость полученных композитов составили $527 \pm 21$ МПа и $158 \pm 6 \mathrm{HV}_{20}$. В тоже время, в [11] приведены данные по структурно-фазовому составу, механическим и трибологическим свойствам композитов на основе сплава АМг2, упрочненного 1 вес.\% нановолокнами $\gamma-\mathrm{Al}_{2} \mathrm{O}_{3}$. Полученные композиты имели условный предел текучести на сжатие 760 МПа. Высокие механические свойства композитов [11], согласуются с моделью Келли [12], согласно которой упрочнение стержнями должно быть более эффективным, чем упрочнение сферами при тех же массах и объемах упрочняющей фазы. Следует учитывать также влияние длины стержней (волокон, нановолокон) на механические свойства композитов [13], поэтому в некоторых случаях необходимо ограничивать их длину для исключения необратимых явлений (потеря устойчивости, разрывы) [14]. Таким образом, использование наполнителя в виде волокон является наиболее целесообразным, позволяя достичь большего эффекта упрочнения. 
Целью настоящей работы является изучение влияния температуры консолидации на структуру и механические свойства порошковых композитов на основе сплава АМг2, упрочненного 1 вес.\% нановолокон $\gamma-\mathrm{Al}_{2} \mathrm{O}_{3}$.

\section{2. Методы}

Исходная шихта представляла собой гранулы глобулярной формы диаметром 1-2 мм из алюминиевого сплава АМг2 с добавлением 1 вес.\% наполнителя. В качестве наполнителя использовали нановолокна $\gamma-\mathrm{Al}_{2} \mathrm{O}_{3}$ диаметром $10-40$ нм (Рис. 1a), которые представляли собой монокристалл (Рис. 1a, вставка) в поле зрения ПЭМ, т.е. по крайней мере, на длине 100-500 нм. Механическая обработка исходной шихты была проведена в планетарной мельнице FRITSCH PULVERISETTE 6 с применением поверхностно активных веществ (стеариновая кислота 1 вес.\%) [15]. Обработку проводили при частоте вращения водила 600 об/мин в течение 6 часов. Гранулометрический состав композиционного порошка определяли на приборе Микросайзер-201С. Консолидация полученного композиционного порошка была выполнена методом спекания под давлением при температуре $t=300,350,400$ и $450^{\circ} \mathrm{C}$, давлении $q=600$ МПа, время выдержки под давлением во всех опытах составляло 300 секунд. Выбор времени консолидации осуществлен опытным путем и обусловлен, с одной стороны, возможностью получения малопористых компактов, с другой - потребностью минимизации влияния изотермической выдержки на изменение структурно-фазового состава синтезируемых композиционных материалов. Измерение плотности консолидированных образцов проводили методом гидростатического взвешивания. Исследования структурно-фазового состава композиционного порошка и консолидированных образцов проводили методом рентгеноструктурного анализа с помощью дифрактометра D8 ADVANCE.

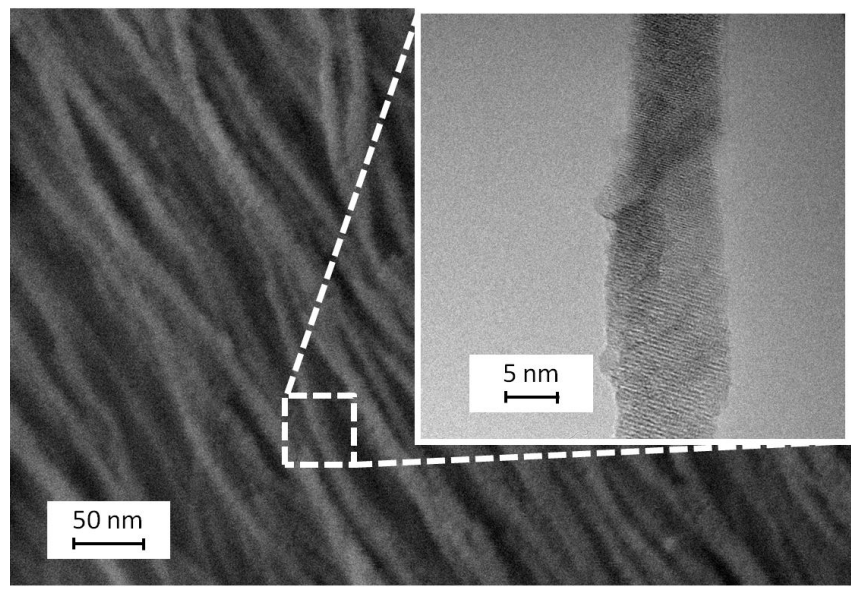

Тонкую структуру наполнителя и консолидированных образцов исследовали с помощью просвечивающего электронного микроскопа JEM-2010. Твердость измеряли методом Виккерса с помощью микротвердомера SHIMADZU HMV-2 при нагрузке на индентор 10 Н и выдержке 12 с. Условный предел текучести при сжатии определяли с помощью машины для механических испытаний WDW-100E, при этом скорость перемещения траверсы составляла $5 \mathrm{~mm} / \mathrm{c}$.

\section{3. Результаты и обсуждение}

Частицы синтезированного композиционного порошка имели неправильную форму, близкую по своей геометрии к осколочной (Рис. 1b). Средний размер формируемых частиц композиционного порошка, содержащего 1 вес.\% нановолокон $\gamma$ - $\mathrm{Al}_{2} \mathrm{O}_{3}$, составил 62 мкм. Результаты рентгеноструктурного анализа показывают, что дифрактограммы композиционного порошка качественно схожи с данными, полученными на матричном материале. Отмечено наличие пиков, соответствующих твердому раствору магния в алюминии. Однако, отсутствуют пики, соответствующие наполнителю. С одной стороны, это может быть обусловлено высокой дисперсностью наполнителя, достигнутой при механической обработке в мельнице, с другой стороны, малой чувствительностью рентгеноструктурного метода к идентификации фаз с содержанием менее $3 \%$. Также, по формуле Селякова-Шеррера [16] был определен размер областей когерентного рассеяния (ОКР). Усредненные по объему размеры ОКР вычисляли исходя из предположения о сферической форме кристаллитов. После обработки в мельнице, размер ОКР композиционного порошка составил 92 нм.

Консолидированные образцы представляли собой плотные цилиндры диаметром 5 мм. Повышение температуры спекания от 300 до $450^{\circ} \mathrm{C}$ способствует росту относительной плотности компактов с 0.87 до 0.98 (Рис. 2).

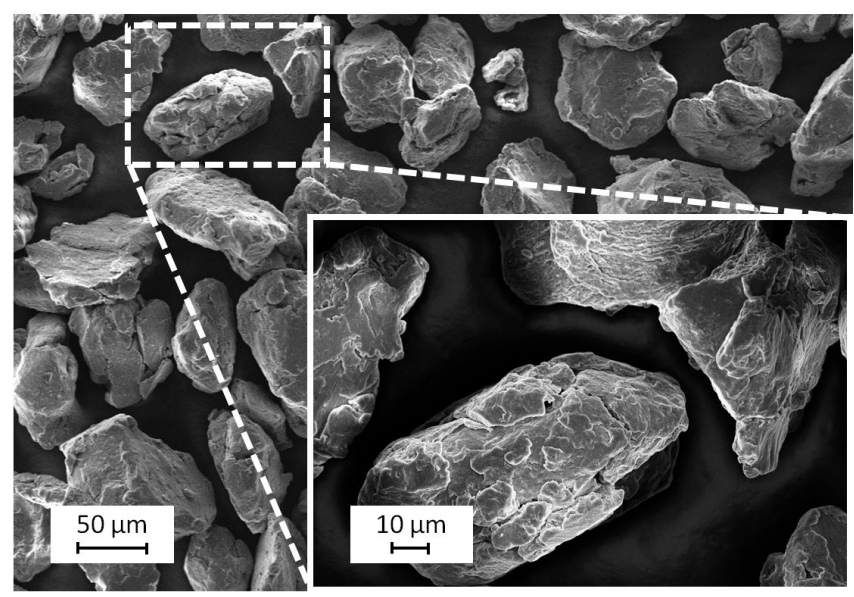

b

Рис. 1. СЭМ-изображения и ПЭМВР-изображения нановолокон $\gamma$ - $\mathrm{Al}_{2} \mathrm{O}_{3}$ (а) и СЭМ-изображения механически синтезированного композиционного порошка АМг2/нановолокна $\gamma-\mathrm{Al}_{2} \mathrm{O}_{3}(\mathrm{~b})$.

Fig. 1. SEM-images and HRTEM-images of $\gamma-\mathrm{Al}_{2} \mathrm{O}_{3}$ nanofibres (a) and SEM-images of a mechanically synthesized AMg2 composite powder/nanofibres $\gamma-\mathrm{Al}_{2} \mathrm{O}_{3}(\mathrm{~b})$. 


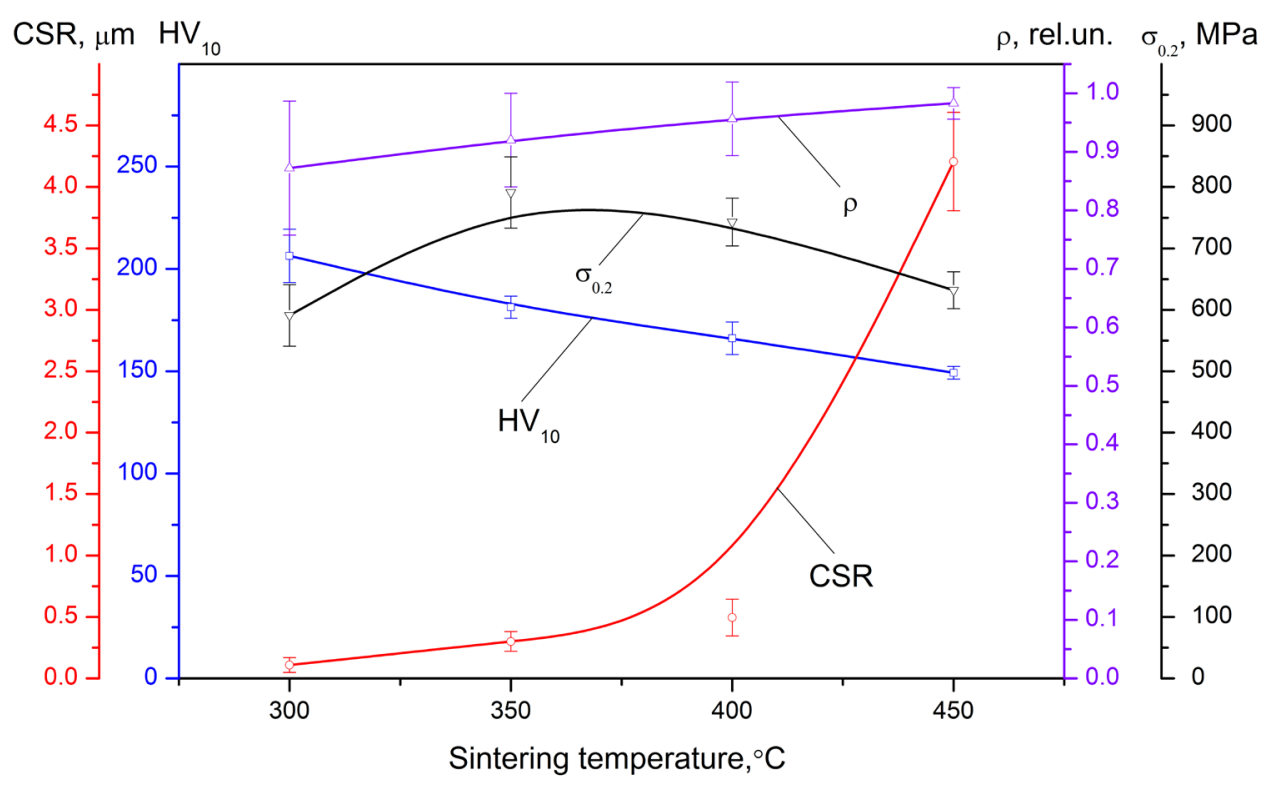

Рис. 2. Влияние температуры консолидации на отностельную плотность, размер ОКР, твердость и условный предел текучести объемных композитов.

Fig. 2. The influence of the consolidation temperature on the relative density, the size of the coherent scattering region (CSR), the hardness and the conditional yield strength of bulk composites.

Увеличение температуры спекания также ведет к снижению величины среднего квадратичного отклонения, т.е. обеспечивает большую однородность при консолидации.

Результаты рентгеноструктурного анализа объемных композитов качественно схожи с данными, полученными на механически синтезированных порошках. Можно выделить уменьшение ширины дифракционных пиков, свидетельствующее о протекании восстановительных процессов в матричном материале при изотермической выдержке. На основании результатов рентгеновской дифрактометрии определены значения ОКР, соответствующие объемным композитам, консолидированным при различной температуре. Сравнительный анализ полученных данных (Рис. 2) показывает, что повышение температуры консолидации от 300 до $400^{\circ} \mathrm{C}$ ведет к линейному росту ОКР от 109 до 495 нм, дальнейшее увеличение температуры до $450^{\circ} \mathrm{C}$ способствует более интенсивному росту ОКР -4.2 мкм. Сопоставляя полученные результаты влияния температуры спекания на размер ОКР с данными работы [17], нужно отметить более интенсивное протекание в консолидируемом порошке восстановительных процессов при использовании в качестве упрочняющей добавки нановолокон $\gamma$ - $\mathrm{Al}_{2} \mathrm{O}_{3}$, чем в случае использования наполнителя в виде частиц нанокристаллического графита.

На Рис. 3 представлены типичные темнопольные ПЭМ-изображения структуры образцов, консолидированных при температуре 300 и $450^{\circ} \mathrm{C}$.

Сравнительный анализ расчетных значений ОКР с данными, полученными с темнопольных ПЭМ-изображений, показывает их хорошее соответствие. Так, например, на ПЭМ-изображении, представленном на Рис. 3 а, видно, что размер зерна изменяется в диапа- зоне 80-130 нм. В то время как для образца, консолидированного при $450^{\circ} \mathrm{C}$ (Рис. $3 \mathrm{~b}$ ), характерна структура с достаточно крупным зерном микрометрического масштаба.

Измерения твердости показывают, что увели-

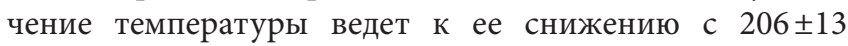
до $149 \pm 13 \mathrm{HV}_{10}$. Снижение твердости при повышении температуры консолидации согласно зависимости Холла-Петча $[18,19]$ объясняется ростом размера зерна, т.е. переходом структуры матричного материала из нанов субмикронный, а при $450^{\circ} \mathrm{C}$ даже микронный масштаб. Соотнесение полученных данных с зависимостями Холла-Петча для сплавов Al-1.5Mg и Al-3Mg, представленными в работах $[20,21]$, показывает, что твердость полученных композитов на $15-55 \%$ выше расчетной. Это обусловлено действием другого механизма упрочнения - Орована $[22,23]$. Нужно отметить увеличение фактической твердости образцов по сравнению с рассчитанной по зависимости Холла-Петча при повышении температуры консолидации. По всей видимости, это связано с полиморфным превращением аморфного $\mathrm{Al}_{2} \mathrm{O}_{3}$ на поверхности частиц порошка в in situ $\gamma-\mathrm{Al}_{2} \mathrm{O}_{3}$, а также увеличении доли последнего с повышением температуры консолидации $[8,24]$. В $[25,26]$ установлено, что полиморфное превращение аморфного $\mathrm{Al}_{2} \mathrm{O}_{3}$ в кристаллическую $\gamma$-модификацию происходит при температуре выше $500^{\circ} \mathrm{C}$. Снижение температуры кристаллизации аморфного $\mathrm{Al}_{2} \mathrm{O}_{3}$ до $450^{\circ} \mathrm{C}$ возможно при увеличении времени термообработки [27]. Интенсивная пластическая деформация также способствует снижению температуры кристаллизации $\gamma-\mathrm{Al}_{2} \mathrm{O}_{3}$ до $400^{\circ} \mathrm{C}[7,8]$. Учитывая, что в данной работе консолидируемые порошки предварительно обрабатывали в планетарной мельнице для которой характерно интенсивное пластическое деформирование 

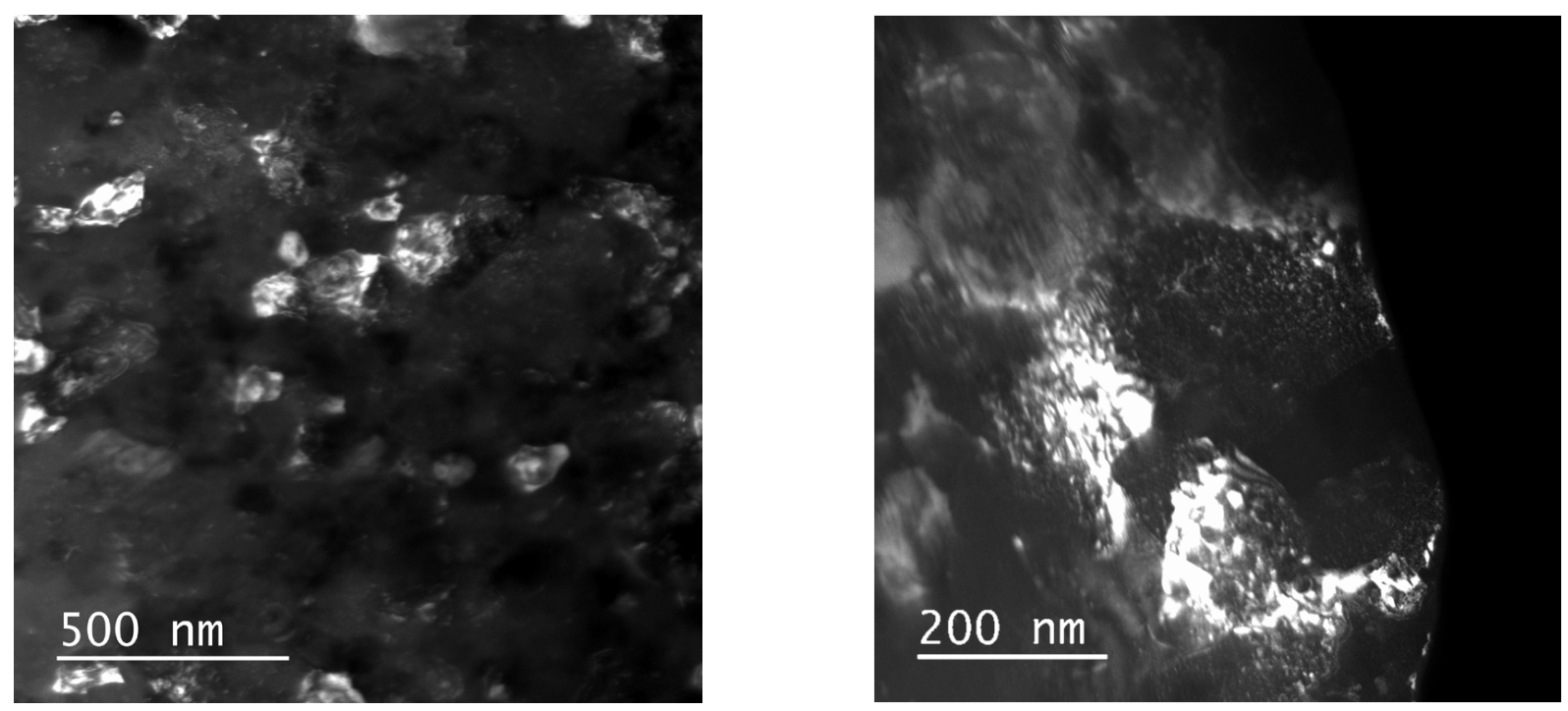

Pис. 3. Темнопольные ПЭМ-изображения структуры образцов, консолидированных при $300^{\circ} \mathrm{C}$ (a) и $450^{\circ} \mathrm{C}(\mathrm{b})$.

Fig. 3. Dark field TEM-images structure of samples consolidated at $300^{\circ} \mathrm{C} \mathrm{(a)} \mathrm{and} 450^{\circ} \mathrm{C}$ (b).

обрабатываемого материала [3,4], кроме дисперсного упрочнения нановолокнами $\gamma$ - $\mathrm{Al}_{2} \mathrm{O}_{3}$ возможно дисперсионное упрочнение in situ $\gamma-\mathrm{Al}_{2} \mathrm{O}_{3}$. Это объясняет увеличение отклонения от Холл-Петча при повышении температуры консолижации. Время изотермической выдержки также оказывает влияние на твердость образцов. С одной стороны, снижая ее за счет роста размера зерна, с другой стороны может вести к увеличению - посредством повышения доли in situ $\gamma-\mathrm{Al}_{2} \mathrm{O}_{3}$ [27].

Наибольшие значения условного преде-

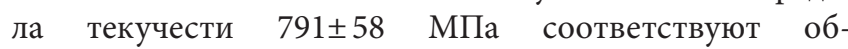
разцам, консолидированным при $350^{\circ} \mathrm{C}$, повышение температуры до $450^{\circ} \mathrm{C}$ ведет к снижению условного предела текучести до $632 \pm 30$ МПа. В тоже время, для образцов, полученных при $300^{\circ} \mathrm{C}$, значения условного предела текучести, в отличии от твердости, были наименьшими 591土38 МПа, а испытуемые образцы разрушались хрупко (без образования площадки текучести). По всей видимости, учитывая данные об относительной плотности, это связано с влиянием пористости и с недостаточной механической прочностью компактов, что не проявлялось при измерении твердости в связи с локальностью деформационного воздействия индентора на испытуемый образец.

Таким образом, повышение температуры спекания под давлением (в рассматриваемом диапазоне) ведет к увеличению среднего размера зерна матричного материала. Это уменьшает количество границ зерен и нивелирует эффект наноструктурирования, достигнутый при механической обработке в планетарной мельнице и как следствие - снижение механических свойств, которое может быть компенсировано за счет образования in situ $\gamma-\mathrm{Al}_{2} \mathrm{O}_{3}$.

Благодарности/Acknowledgements. Исследование выполнено при бинансовой поддержке РФФИ в рамках научного проекта №17-38-50109 «мол_нр»./The study was carried out with the financial support of the RFBR in the framework of the scientific project No. 17-38-50109 «mol_nr».

\section{Литература/References}

1. S.C. Tjong. Adv.Eng. Mater. 9, 639 (2007). DOI: 10.1002/adem.200700106

2. R. Casati, M. Vedani. Metals. 4 (1), 65 (2014). DOI: $10.3390 /$ met4010065

3. C. Suryanarayana. Progr. Mater. Sci. 46, 1 (2001).

4. C. Suryanarayana, N. Al-Aqeeli. Progr. Mater. Sci. 58 (4), 383 (2013). DOI: 10.1016/j.pmatsci.2012.10.001

5. Y-C. Kang, S. L.-I Chan. Materials Chemistry and Physics. 85, 438 (2004). DOI: $10.1016 /$ j.matchemphys.2004.02.002

6. D. Poirier, R.A. L. Drew, M.L. Trudeau, R. Gauvin. Materials Science and Engineering A. 527, 7605 (2010). DOI: $10.1016 /$ j.msea.2010.08.018

7. W. $\mathrm{Xu}, \mathrm{T}$. Honma, X. Wu, S.P. Ringer, K.Xia. Appl. Phys. Lett. 91, 031901 (2007). DOI: $10.1063 / 1.2755923$

8. W. Xu, X. Wu, T. Honma, S.P. Ringer, K.Xia. Acta Materialia. 57, 4321 (2009). DOI: $10.1016 /$ j.actamat.2009.06.010

9. R. Casati, A. Fabrizi, A. Tuissi, K. Xia, M. Vedani. Materials Science and Engineering A. 648, 113 (2015). DOI: 10.1016/j.msea.2015.09.025

10. K. Kallip, N. K. Babu, K.A. AlOgab, L. Kollo, X. Maeder, Y. Arroyo, M. Leparoux. Journal of Alloys and Compounds. 714, 133 (2017). DOI: 10.1016/j.jallcom.2017.04.233

11. A. V. Aborkin, D. M. Babin, A. V. Sobol kov. IOP Conf. Ser.: Material Science and Engineering. 347, 012037 (2018). DOI: 10.1088/1757-899X/347/1/012037

12. P. M. Kelly. Scripta Metallurgica. 6 (8), 647 (1972).

13. R.W. K. Honeycombe. Plastic Deformation of Metals. Hodder Education Group. (1984) 496 p.

14. V. Kukhar, V. Artiukh, A. Prysiazhnyi, A. Pustovgar. E3S Web of Conference. 33, 02031 (2018). DOI: $10.1051 /$ e3sconf/20183302031

15. A. V. Aborkin, M.I. Alymov, A.V. Kireev, A.I. Elkin, A. V. Sobol'kov. Nanotechnologies in Russia. 12 (7-8), 395 (2017). (in Russian) [А. В. Аборкин, М.И. Алымов, 
А.В. Киреев, А.И. Елкин, А.В. Собольков. Российские нанотехнологии. 7-8, 66. (2017).] DOI: $10.1134 /$ S1995078017040024

16. V.N. Selivanov, E.F. Smyslov. Industrial Laboratory. 59 (6), 36 (1993). (in Russian) [В.Н. Селиванов, Е.Ф. Смыслов. Заводская лаборатория. 59 (6), 36 (1993).]

17. A.V. Aborkin, M.I. Alymov, A.V. Sobol'kov, K.S. Khor'kov, D.M. Babin. Russian Metallurgy (Metally). 2018 (7), 625 (2018). (in Russian) [А.В. Аборкин, М.И. Алымов, А.В. Собольков, К.С. Хорьков, Д. М. Бабин. Металлы. 4, 27 (2018).] DOI: $10.1134 /$ S0036029518070029

18. C. S. Pande, K. P. Cooper. Progr. Mater. Sci. 54, 689 (2009). DOI: $10.1016 /$ j.pmatsci.2009.03.008

19. T.H. Courtney. Mechanical Behavior of Materials. McGraw-Hill Book Co. (2000) 733 p.
20. M. Furukawa, Z. Horita, M. Nemoto, R.Z. Valiev, T. G. Langdon. Acta Mater. 44 (11), 4619 (1996).

21. M. Furukawa, Z. Horita, M. Nemoto, R.Z. Valiev, T. G. Langdon. Philos. Mag. A. 78, 203 (1998).

22. Z. Zhang, D. L. Chen. Mater. Sci. Eng. A. $483-484,148$ (2008). DOI: 10.1016/j.msea.2006.10.184

23. Z. Zhang, D.L. Chen. Scripta Mater. 54, 1321 (2006). DOI: 10.1016/j.scriptamat.2005.12.017

24. L.P. H. Jeurgens, W.G. Sloof, F.D. Tichelaar, E. J. Mittemeijer. Phys. Rev. B. 62, 4707 (2000).

25. T.C. Chou, D. Adamson, J. Mardinly, T.G. Nieh. Thin Solid Films. 205, 131 (1991).

26. T. G. Nieh, P. Luo, W. Nellis, D. Lesuer, D. Benson. Acta Mater. 44, 3781 (1996).

27. M. Balog, P. Krizik, M. Nosko, Z. Hajovska, M. V. Castro Riglo, W. Rajnerc, D.-S Liu, F. Simancik. Mater. Sci. Eng. A. 613, 82 (2014). DOI: 10.1016/j.msea.2014.06.070 